\title{
RANCANG BANGUN ALAT PEMBERI PAKAN IKAN DENGAN SISTEM AUTOMATISASI BERBASIS ARDUINO UNO R3 DENGAN SISTEM KENDALI SMS
}

\author{
Ardiwijoyo'), Jamaluddin2) dan Abd. Muis Mappalotteng3) \\ ${ }^{1}$ Alumni Program Studi Pendidikan Teknologi Pertanian \\ ${ }^{2}$ dan ${ }^{3}$ Dosen PTP FT UNM
}

\begin{abstract}
ABSTRAK
Penelitian ini bertujuan untuk membuat rancang bangun pemberi pakan secara otomatis berbasis Board Arduino yang dapat diterapkan pada kolam ikan dan untuk mengimplementasikan rancag bangun pemberi pakan ikan secara otomatis untuk budidaya ikan. Metode penelitian ini menggunakan Research andDevelopment (R\&D), hasil penelitian diolah dengan menggunakan teknik analisis data kuantitatif dengan statistik deskriptif dan data yang diperoleh dideskripsikan untuk membahas uji kerja dan keberhasilan dari alat. Hasil uji coba alat pemberi pakan ikan otomatis melalui beberapa mekanisme diantaranya pembuatan rangka, pemasangan komponen bahan serta pembuatan sistem mikrokontroler yang meliputi; pembuatan jalur rangkaian, pemasangan komponen, dan pengimputan bahasa program pada sistem mikrokontroler. Pemberian pakan ikan berbasis mikrokontroler belum dapat berjalan dengan efektif dan efesian jika dibandingkan dengan pemberi pakan manual yang dilakukan oleh manusia.
\end{abstract}

Kata Kunci: Alat Pemberi Pakan, Arduino Uno R3,dan SMS

\begin{abstract}
The aim this study to make the design of fish feeding device that autometically based Arduino Board that can be applied in fish pond and to implement the design of fish feeding device that autometically for fish cultivation. The method used in the study in Research and Development $(R \& D)$, the result of research processed used quantitative data analysis techniques with several mechanisms such as made a framework, the installation of material components and manufacturing of microcontroller systems which includes making the path of series, the installation of components and inputting language program in microcontroller system. The device of fish feeding based mirocontroller can not be effective and effecient if compared with feeding manually that done by human.
\end{abstract}

Keywords : Feeding Tool, Arduino Uno R3, and SMS

\section{PENDAHULUAN}

Usaha budidaya ikan menjadi
salah satu upaya penopang
perekonomian masyarakat di tengah
sulitnya lapangan pekerjaan maupun
tuntutan kebutuhan yang meningkat.

Selain untuk mendapatkan keuntungan dari penjualan daging ikan juga sebagai sarana hiburan seperti usaha pemancingan yang marak berkembang di saat ini. Pada dasarnya, untuk meningkatkan hasil budidaya serta mempermudah kegiatan budidaya, maka 
perlu adanya pengembangan teknologi di dalamnya, menurut Hendra. dkk (2015). Perkembangan ilmu dan teknologi berpengaruh besar, baik yang berhubungan dengan rutinitas manusia secara langsung maupun rutinitas secara tidak langsung.

Pakan mempunyai peranan sangat penting dalam pertumbuhan dan perkembangbiakan budidaya ikan. Perkembangan teknologi digital memberikan solusi dalam sebuah sistem otomatis yang lebih baik. Rancang bangun pemberi pakan otomatis berbasis mikrokontroler adalah salah satu sistem elektronik yang dirancang untuk memberikan pakan secara otomatis pada kolam ikan. Sistem ini dikendalikan menggunakan board arduino, jadi katup selenoid dari alat akan bergerak sesuai dengan waktu yang sudah ditentukan oleh pengguna dan ketika pakan sudah hampir habis, maka secara otomatis alat akan memberikan sinyal berupa sms kepada pengguna bahwa pakan sudah hampir habis, sehingga pengguna dapat mengantisipasi pakan yang akan habis. Hal tersebut merupakan penerapan dari sistem automasi/ kontrol otomatis yang dimana menurut Muksin (2010). Mikrokontroller atau bisa juga disebut dengan single chip mikrokomputer karena mikrokontroller ini dapat langsung digunakan sebagai unit pengontrol tanpa komponen lain sebagai pendukung lainnya.

Biasanya Mikrokontroller ini digunakan untuk aplikasi-aplikasi khusus yang sudah di program dari pabrikpabrik.

Perancangan sistem pakan otomatis ini diusahakan menggunakan piranti seminimal mungkin guna dapat diterapkan pada objek yang sesungguhnya. Sistem yang di rakit terdiri atas 1 buah katub selenoid, LCD, dan sistem kendali. Sistem pakan otomatis ini menggunakan katub solenoid sebagai penggerak utama, sehingga pakan dapat dikeluarkan ketika katub solenoid membuka katup corong wadah pakan dan pakan akan keluar secara otomatis.

Teknologi remote control telah banyak dikembangkan dengan memanfaatkan berbagai media transmisi. Beberapa diantaranya adalah remote control dengan memanfaatkan media ultrasonik, gelombang radio, internet dan saluran telepon. Sistem remote control melalui saluran telepon memiliki keunggulan dalam hal jarak jangkauan dan kepraktisan dibanding media lainnya Haerul dan Septiadi (2015). Mikrokontroler sebagai otak / pengendali utama yang dipadukan dengan modul Modem Wavecoom de program agar terkoneksi dengan handphone pengguna untuk memantau kondisi jumlah pakan. Display LCD akan menampilkan status sistem yang sedang aktif dan pengaturan waktu yang akan dilakukan. Menurut Hendra. Dkk (2015) sistem kendali ini menggunakan mikrokontroller ATMega 328 yang masih merupakan keluarga mikrokontroller DI-SMART AVR SYSTEM merupakan sebuah modul yang digunakan untuk jenis AVR 
ATmega8535(L), ATmega32(L), AT mega163(L), ATmega323(L) dengan basis mikrokontroler AVR (Automatic voltage regulator) dan memiliki pemograman memori melali ISP (InSystem Programming). Mikrokontroler ini adalah 8-bit CMOS yang memiliki 512 Byte Flash Rom yang dapat langsung deprogram dan juga dihapus.

Dengan memanfaatkan fungsifungsi tersebut di atas maka dibuatlah alat yang berfungsi untuk memberi pakan ikan secara otomatis, sehingga member kemudahan untuk para pemilik ikan dalam memberikan pakan kepada ikan peliharaannya jika berada di tempat yang jauh dari miliknya.

Diharapkan dengan perancangan sistem pengendali otomatis ini mampu membantu dalam pemberian pakan ikan. Berdasarkan latar belakang yang telah diuraikan di atas, maka judul dari penelitian ini yaitu“ Rancang Bangun Alat Pemberi Pakan Ikan dengan Sistem Automatisasi Berbasis Arduino Uno R3 dengan Sistem Kendali SMS".

\section{TUJUAN PENELITIAN}

Adapun tujuan yang akan dicapai dalam penelitian ini adalah sebagai berikut:

1. Mengetahui unjuk kerja dari alat pemberi pakan ikan otomatis yang dapat diterapkan pada kolam ikan.

2. Untuk Mengimplementasikan rancang bangun pemberi pakan ikan secara otomatis untuk budidaya ikan.

\section{METODE PENELITIAN}

\author{
Metode Pendekatan dan Pembuatan \\ Alat
}

Metode pendekatan yang

digunakan pada pembuatan alat ini yaitu metode Research and Development (R\&D). $R \& D$ adalah metode penelitian yang digunakan untuk menghasilkan produk tertentu, dan menguji keefektifan produk tersebut. Menurut Sujadi (2003) Research and Development (R\&D) adalah suatu proses atau langkahlangkah untuk mengembangkan suatu produk baru, atau menyempurnakan produk yang telah ada, yang dapat dipertanggungjawabkan.

Secara umum, metode pendekatan penelitian R\&D seperti yang terlihat pada gambar 5 dalam merancang alat pemberi pakan ini dimulai dari tahap identifikasi masalah sampai dengan pengujian alat yang akan dijelaskan sebagai berikut:

1. Mengindentifikasi Masalah

Tahap pertama yaitu megidentifikasi masalah yang ada di lapangan untuk menentukan berbagai macam kebutuhan konstruksi, model, dan implementasi alat.

\section{Perancangan Sistem Mekanik}

Perancangan sistem mekanik bertujuan untuk menghasilkan bentuk konstruksi alat, pada tahap ini dilakukan proses perancangan dan perakitan sistem mekanik agar alat dapat menjalangkan fungsi utamanya secara mekanis.

a. Perancangan Sistem Minimum dan Pemrograman 
Perancangan sistem minimum dan pemrograman dilakukan pada mikrokontroler / arduinouno R3 dengan tujuan agar keseluruhan sistem kontrol dapat bekerja secara terstruktur sesuai dengan sistem mekanik yang telah dirancang, pemrograman dilakukan dengan menggunakan bahasa $\mathrm{C}+$.

b. Tahap Pengujian Sistem

Tahap terakhir yaitu pengujian sistem pemberi pakan dan sistem kontrol untuk mengetahui kinerja atau integrasi dari alat yang telah dibuat. Apabila masing-masing komponen dan perangkat dapat bekerja sesuai dengan prinsipnya,

\section{Gambar Desain Produk}

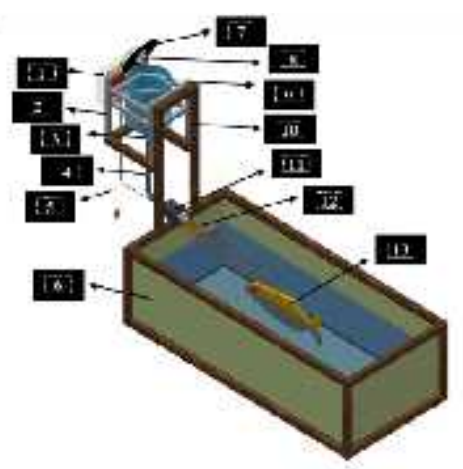

Keterangan :

1. Sistem minimum

2. Tiang dudukan

3. Dop pipa

4. Pipa

5. Kabel jumper

6. Bejana penampungan

7. Penutup bejana

8. Sensor ultrasonic

9. Botol galon $4 \mathrm{~L}$

10. Tiang alat

11. Saluran pakan

12. Pakan

13. Ikan

\section{Alat dan Bahan}

Pada proses pembuatan alat perlu dipersiapkan alat dan bahan sebelum dilakukan atau dikerjakan agar dalam proses pengerjaannya berjalan lancer. Beberapa alat dan bahan yang dibutuhkan yaitu:

\section{Alat}

Alat-alat yang digunakan untuk perancangan adalah sebagai berikut:
a. Mesin Gurinda
b. Mesin Bor
c. Mata Bor $3 \mathrm{~mm}$
d. Mata bor $40 \mathrm{~mm}$
e. Penembak Lem Lilin
f. Solder
g. Balok
h. Smartphone
i. Laptop/PC

\section{Bahan}

Bahan- bahan yang digunakan untuk perancangan adalah sebagai berikut:

a. Komponen Mekanik
1) Alkopan
2) Tima
3) Lem Lilin
4) Botol Galon 2 Liter
5) Akrilik $2 \mathrm{~mm}$
6) Sekrup
7) Spacer Pendek
8) Pipa 5 inci
9) Engsel Miniz

b. Komponen Sistem Kontrol
1) Board arduino Uno R3
2) $L C D$
3) Push Button
4) Kabel Jumper
5) Katub selenoid
6) Sensor Ultrasonic 
7) I2C Modul

8) Led $3 \mathrm{~mm}$

9) Buzer

10) Modem Wavecoom

11) Real Time Clock (RTC)

12) Kabel USB

\section{Prosedur Rancang Bangun}

Adapun prosedur perancangan pada penelitian ini adalah sebagai berikut :

1. Persiapan
a. Permintaan izin penggunaan laboratorium/workshop.
b. Membuat rencana/rancangan penelitian.
c. Menyiapkan alat dan bahan yang akan digunakan.

2. Pembuatan Instalasi Alat
a. Menentukan komponen dasar dari instalasi alat.
b. Menggambar sketsa dari Instalasi alat yang akan dibuat.
c. Menyiapkan alat dan bahan yang akan digunakan dalam proses perakitan.
d. Merakit instalasi dari alat sesuai dengan gambar sketsa yang telah dibuat.

3. Pembuatan Rangkaian Sistem Kontrol
a. Menentukan Komponen inti yang akan digunakan dalam sistem kontrol.
b. Menggambar sketsa alur dari rangkaian kontrol yang akan digunakan pada instalasi alat.
c. Menyiapkan alat dan bahan yang akan digunakan dalam perakitan sistem kontrol.
d. Melakukan proses perakitan alur rangkaian kontrol

berdasarkan gambar sketsa sistem kontrol yang sudah dibuat.

\section{Uji Coba Produk}

Prosedur uji coba yang akan dilakukan dalam pembuatan alat iniadalahsebagaiberikut:
a. Menguji coba rangkaian elektronik sistem minimum.
b. Menguji sms gateway setelah menguji pada rangkaian sistem minimum.
c. Menguji perintah yang dikirim dapat diproses mikrokontroler ATmega 3285

d. Menguji katub selenoid berfungsi secara baik atau tidak.

\section{Teknik Analisis Data}

Teknik analisis data yang digunakan pada penelitian ini adalah teknik analisis data kuantitatif dengan statistik deskriptif, data yang diperoleh dideskripsikan untuk membahas uji kerja dan keberhasilan dari alat.

\section{HASIL PENELITIAN}

\section{Hasil Uji Coba}

\section{Hasil Pengujian Sistem Secara Keseluruhan}

Pengujian sistem dari alat yang dibuat berfungsi untuk melihat kinerja dari alat/sistem yang terpasang. Alat akan diberikan tegangan kerja untuk melihat kinerja dari sistem minimum modul sistem kontrol pemberi pakan ikan otomatis beserta program yang telah dimasukkan. Pengujian dilakukan secara bertahap untuk menentukan parameter- 
paramter dan indikator dari pengujian dari sistem.

Pada pengujian sistem minimum yang telah dilarutkan, maka secara visual jalur rangkaian serta mengecek jalur yang short dengan avometer. Semua jalur rangkaian terhubung dengan baik dan avometer tidak mendeteksi jalur yang short. Sehingga pengujian berhasil dilakukan. Pengujian regulator 7805 dalam mengubah tegangan kerja, memberikan tegangan $12 \mathrm{~V}$ dari batteray lipo. Sehingga power indikator arduino uno menyala. Pengujian LCD (liquid crystal display), memberi tegangan di arduino uno yang terpasang di sistem minimum, dan muncul tulisan atau karakter pada LCD yang sesuai dengan input program yang telah dilakukan. pengujian tampilan menu pada LCD, dengan menekan tombol up/ok dan down, kursor pada LCD berpindah pada satu menu ke menu yang lain dan setiap menu dapat masuk ke sub menunya begitupun sebaliknya. Pengujian main program pada masingmasing sub menu dari menu utama, dengan menekan tombol ok pada menu utama, pada menu 1 "Mode Ototmatis" menunjukan mode untuk mengaktifkan pemberi pakan secara otomatis berdasarkan periode waktu tertentu, menu 2 "Set Timer" menunjukan pengaturan untuk waktu pemberian pakan, dan menu 3 "Delay Pakan" menunjukan pengaturan waktu terbukanya penutup atau katup pemberi pakan yang nilai waktunya bisa diatur. Pengujian sensor-sensor ultrasonic, memberikan perlakuan berupa benda yang diletakkan didepan sensor, sehingga jarak antara benda dengan sensor jarak terbaca dalam nilai satuan sentimeter, jarak yang terbaca berdasarkan hasil pemantulan gelombang ultrasonicoleh transmitter dan ditangkap kembali oleh modul receiver.Pengujian trimpot LCD, memberikan putaran searah dan kebalikan dari jarum jam, memberikan kontras dari tulisan pada LCD bertambah dan berkurang seiring perputaran trimpot. Pengujian modul GSM Sim800i V.2, dengan memasang SIM Card pada GSM modul dan wadah pakan dibiarkan kosong agar sistem memerintahkan GSM modul untuk mengirim SMS, GSM modul mengirim SMS kepengguna "Nomor yang telah dimasukkan" bahwa pakan telah habis dan harap segera isi ulang pakan. Pengujian katup penutup (motor servo) dari corong pengeluaran pakan, memberikan perlakuan pada sistem agar instruksi dapat diketahui saat mengeluarkan pakan, dan katup penutup corong terbuka berdasarkan jeda waktu yang telah ditetapkan pakan keluar dengan cepat. Pengujian modul RTC, memberikan tegangan pada sistem kontrol dan masuk ke mode set timer, saat masuk ke mode set timer LCD menampilkan indicator waktu yang sedang berjalan mulai dari jam, menit, dan detik. Pengujian relay, memberikan tegangan AC 220V, dan memberikan sinyal digital dari mikrokontroler dengan tegangan DC 5V, relay memberikan respon sesuai dengan masukan dari sinyal digital untuk menyalakan actuator yang di tandai dengan bunyi "tek" serta 
indicator lampu led ketika menyala dan mati. Pengujian modul ESC "electronic speed controller", memberi tegangan 12V DC pada kutub positif dan negative pada ESC, saat mendapat tegangan $12 \mathrm{~V}$ DC, ESC memberikan pada ESC, saat mendapat tegangan $12 \mathrm{~V}$ DC, ESC memberikan respon berupa bunyi "bip" sebanyak 3 kali yang menandakan bahwa ESC dan motor brushless terkoneksi dengan baik serta siap untuk digunakan. Bunyi "bip" kurang dari 3 kali mendakan bahwa ESC dan motor tidak terkoneksi. Pengujian motor brushless (motor pelontar pakan) merk RCX 1806 2400K V, memberi tegangan $12 \mathrm{~V}$ DC pad ESCdan memberikan instruksi pada sistem kontrol untuk mengeluarkan pakan, motor brushless yang menggunakan baling-baling melontarkan pakan dengan cara mengehembuskan angina pada pakan yang keluar sehingga pendistribusian pakan berlangsung secara maksimal.

\section{Pengujian Kinerja Alat (Kapasitas).}

Pengujian dilakukan dengan cara mengatur waktu proses pemberian pakan untuk melihat kuantitas pakan yang keluar pada satuan waktu tertentu. Waktu yang digunakan yaitu 3 detik, 5 detik, dan 7 detik dengan masing-masing ulangan sebanyak 3 kali.

a. Pengujian selama 3 detik

\begin{tabular}{|c|c|c|}
\hline No. & PLNOLL:LNGIN & RMLAI PAKAL (GRUM) \\
\hline I & Peaguhngas 1 & 38.2 \\
\hline 2 & Peagulangas 2 & 37.8 \\
\hline 3 & Payquanga 3 & 39 \\
\hline
\end{tabular}

Berdasarkan hasil pengujian selama 3 detik menunjukkan pakan yang keluar sebanyak tiga kali pengulangan yaitu, pada pengujian ke-1 mempunyai rata-rata 38,3 gram, pengujian ke-2 mempunyai rata-rata 37,8 gram,dan pengujian ke-3 mempunyai rata-rata 39 gram.

b. Pengujian selama 5 detik

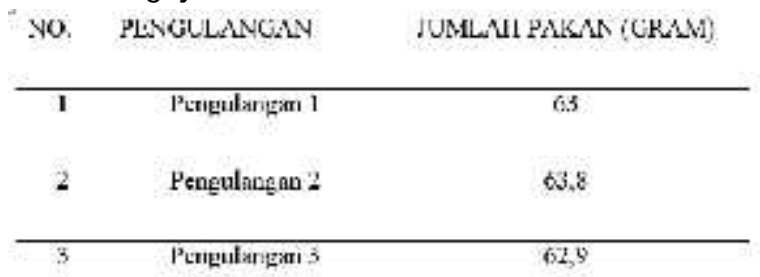

\section{Berdasarkan hasil pengujian} selama 5 detik menunjukkan pakan yang keluar sebanyak tiga kali pengulangan yaitu, pada pengujian ke-1 mempunyai rata-rata 63 gram, pengujian ke-2 mempunyai rata-rata 63,8 gram dan pengujian ke-3 mempunyai rata-rata 62,9 gram.

c. Pengujian selama 7 detik

\begin{tabular}{|c|c|c|}
\hline No. & PFINGTIT.ANGTAX & TINI AH PAKAN (GR.AMT) \\
\hline 1 & Peryzlangan I & 88,2 \\
\hline 2 & Pergulangan 2 & $8 \overline{8}, 8$ \\
\hline 3 & Pengulangan 3 & ig \\
\hline
\end{tabular}

Berdasarkan hasil pengujian selama 7 detik menunjukkan pakan yang keluar sebanyak tiga kali pengulangan yaitu, pada pengujian ke-1 mempunyai rata-rata 88,2 gram pengujian ke-2 mempunyai rata-rata 87,8 gram dan pengujian ke-3 mempunyai rata-rata 89 gram. 


\section{Revisi Produk}

Alat pemberi pakan ikan merupakan teknologi tepat guna yang masih membutuhkan banyak masukan dan perbaikan, mulai dari bahan yang digunakan, bentuk dari komponen alat sampai dengan kapasitas kerja alat yang dihasilkan. Penggunaan teknologi tepat guna diharapkan dapat membantu masyarakat khususnya untuk wilayah perairan dan perikanan agar lebih menghemat waktu dalam proses pemberian pakan ikan.

Bahan dan alat yang digunakanharus lebih terjangkau dan mudah didapatkan dipasaran untuk mempermudah produksi alat. Perancangan alat pemberi pakan ikan juga haru smemperhitungkan biaya produksi, namun tidak menurunkan kualitas dari fungsi alat yang digunakan. Komponen dari peralatan yang digunakan membutuhkan beberapa tambahan seperti komponen sistem minimum dan rangka yang tersusun rapi dan sederhana serta memiliki tekanan yang kuat sehingga pakan yang keluar bisa merataatau pun penambahan mesin penggerak untuk penggunaannya dapat mengefisienkan besar kekuatan dari pemberian pakan.

Selainitu, untuk meningkatkan hasil produksi dan efektifitas dari alat, harusdilakukanmodifikasi lanjutan terhadap alat pemberi pakan otomatis ini. Perancangan komponen alat selanjutnya diharapkan memiliki tingkat kemampuan produksi yang lebih bagus disbanding dengan alat yang telah dirancang.

\section{Kajian Produk Akhir}

Produk akhir rancang bangun ini adalah tercipta sebuah alat pemberi pakan ikan dengan sistem automatisasi berbasis Arduino Uno R3 dengan system kendali SMS. Fungsi dari alat ini yaitu sebagai alat salahsatu system elektronik yang dirancanguntukmemberikan pakan secara otomatis pada kolam ikan. Sistem ini dikendalikan menggunakan board arduino, fungsi darialat ini akan bergerak sesuai dengan waktu yang sudah ditentukan oleh pengguna dan ketika pakan sudah hampir habis, maka secara otomatis alat akan memberikan sinyal berupa sms kepada pengguna bahwa pakan sudah hampir habis, sehingga pengguna dapat mengantisipasi pakan yang akan habis.

Keuntungan alat pemberi pakan secara otomatis ini yaitu memudahkan dalam proses pemberian pakan ikan. Alat ini membantu memberi pakan sehingga proses pemberian pakan pada ikan tidak lagi dilakukan secara manual, pada alat ini terdapat mode timer dimana alat akan terbuka dan menghamburkan pakan sesuai dengan waktu yang ditentukan dan jika pakan hampir habis maka alat ini secara otomatis mengirimkan pesan ke nomor handphone yang telah terdaftar, sehingga dengan mode tersebut pengguna dapat melakukan proses pekerjaan yang lain dengan waktu bersamaan. 


\section{KESIMPULAN}

Berdasarkan dari hasil penelitianRancang Bangun Alat Pemberi Pakan Ikan dengan Sistem Automatisasi Berbasis Arduino Uno R3 dengan Sistem Kendali SMS, dapat ditarik kesimpulan sebagai berikut:

1. Perancangan alat pemberi pakan ikan otomatis melalui beberapa mekanisme diantaranya pembuatan rangka, pemasangan komponen bahan serta pembuatan sistem mikrokontroler yang meliputi pembuatan jalur rangkaian, pemasangan komponen dan pengimputan bahasa program pada sistem mikrokontroler.

2. Pemberian pakan ikan berbasis mikrokontroler dapat bekerja secara ergonomis sesuai dengan yang direncanakan.

\section{SARAN}

Berdasarkan hasil pengujian alat yang telah dilakukan, maka peneliti menyarankan:

1. Melakukan modifikasi pada alat pemberi pakan ikan otomatis berbasis mikrokontroler dengan penambahasan pembaharuan terbaru sehingga dapat menghasilkan tekanan pada proses keluarnya pakan.

2. Disarankan kepada peneliti selanjutnya untuk melakukan pengembangan alat rekayasa berbasis mikrokontroler yang lain untuk memudahkan proses penanganan hasil untuk bidang perikanan.

\section{DAFTAR PUSTAKA.}

Hairul dan Isman septiadi 2015. "Desain Kontrol Alat Pemberi Pakan Ikan HiasBerbasis Mikrokontroler Atmega8 Melalui Sms". Skripsi tidak diterbitkan. Makassar : Universitas Negeri Makassar.

Hendra. S. Weku, Dr.EngVecky C Poekoel, ST., MT.,Reynold F. Robot, ST.,M.Eng.2015. Rancang Bangun Alat Pemberi Pakan Ikan Otomatis Berbasis Mikrokontroler. Jurusan Teknik Elektro-FT, UNSRAT, Manado. (Online).http://ejournal.unsrat.ac.id /index.php/elekdankom/article/dow nload/10706/10294. Diakses 18 agustus 2016.

Muksin, M. 2010."Simulasi Alat Pemberi Pakandan Pengendalian Kincir Air yang berdasarkan Suhu dan Kadar Oksigenpada Kolom ikan gurami Berbass MCU AT89C51". Widya Teknika Vol. 18 No.

Sujadi. 2003 "Research and Development (R\&D)". (Online). Ejournal.

http://journal.sttnas.ac.id/index.ph $\mathrm{p} /$ ReTII/article/download/134/106.

Diakses 21 agustus 2016. 